\title{
Prevalence of Zygomatic air cell defect: A panoramic radiographic study
}

Ankita Bohra', Basavraj T Bhagwati ${ }^{2}$, Neelkant Patil ${ }^{3}$, Anitha $B^{4}$, Sumit Bhateja ${ }^{5}$

\section{Quick Response Code}

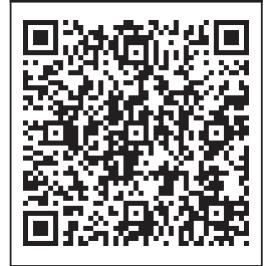

doi: $10.5866 / 2015.7 .10097$

${ }^{1}$ Post Graduate

2Professor \& Head

${ }^{3} \& 4$ Reader

${ }^{5}$ Senior lecturer

Oral medicine \& Radiology,

Vyas Dental College \& Hospital,

J odhpur, Rajasthan.

\section{Article Info:}

Received: April 12, 2015

Review Completed: May 11, 2015

Accepted: J une 12, 2015

Available Online: April, 2015 (www.nacd.in)

(C) NAD, 2015 - All rights reserved

\section{E mail for correspondence:}

aav1423@hotmail.com

\begin{abstract}
:
BACKGROUND: Pneumatized air cells present in the zygomatic process of the temporal bone, which appears similar to the mastoid air cells and which does not extend further anteriorly than the zygomatico-temporal suture, entitled as zygomatic air cell defect (ZACD).
\end{abstract}

AIMS: To determine the prevalence, patterns of occurrence and variations of zygomatic air cell defects (ZACDs) according to age and gender using panoramic radiographs.

METHODS AND MATERIALS: Dental panoramic radiographs of 1000 outpatients between age group of 20 to 60 (and above) were divided into 5 groups \& examined to evaluate the variations \& characteristics of ZACDs in the population.

RESULTS: ZACDs wereidentified in 30 subjects out of 1000, giving an overall prevalence of 3.0\%. Eighteen ZACDs were seen in males and twelve in females. Among the 30 ZACDs, seventeen were unilateral and thirteen were bilateral.

CONCLUSION: Careful radiographicevaluation is needed to detect these entities. It is important for dinicians who are planning to perform temporomandibular joint surgery to assess radiographic imaging thoroughly before the surgery to avoid intra-operative complications.

Key words: zygomatic air cell defect, panoramic radiography, intra-operative complications.

\section{INTRODUCTION}

Pneumatized air cells present in the zygomatic process of the temporal bone, which appears similar to the mastoid air cells and which does not extend further anteriorly than the zygomatico-temporal suture, entitled as zygomatic air cell defect (ZACD).
The word coined by Tyndall and Matteson in the year 1987. Three types of ZACD appearance based on their panoramic radiographic appearance, proposed by Tyndall and Matteson in the year 1985 and has been further used by Carter and coworkers as: (1) Unilocular type; (2) Multilocular type and (3) Trabecular type. ${ }^{1,2}$ 
A unilocular ZACD appears as radiolucency with well defined borders, while the multilocular type demonstrates numerous small cavities within, which resemble mastoid air cells. The trabecular variety is basically a multilocular entity with internal bony striations. ${ }^{1,2}$

When ZACDs have been demonstrated preoperatively on a radiograph, these may become contraindication to performing surgical procedures such as eminoplasty or eminectomy for the treatment of mandibular dislocations as they can become potential pathways for intracranial infections. The present study was aimed to determine the prevalence, patterns of occurrence and variations of zygomatic air cell defects (ZACDs) according to age and gender using panoramic radiographs.

\section{Materials and Method}

Routine panoramic radiographs of 1,000 patients who had visited the Vyas Dental College \& hospital, J odhpur, Rajasthan, from October 1, 2013 to March 31, 2014 were examined retrospectively. 1,000 patients ( 500 females, 500 males) were divided into 5 groups. Each group consisted of 200 patients (100 males, 100 females in each group). Group I consisted of subjects in the age range of 20-29 years, group II in the age range of 30-39 years, and group III in the age range of 40-49 years, group IV in the range of 50-59 years and group $V$ in the range of individuals of 60 years and above, were included. Subjects with developmental malformations of the face and jaws, those in whom systemic conditions had affected growth, those with clinical or radiographic evidence of pathologies in the maxillofacial region, and those with a history of trauma to the maxillofacial region, who had been treated with surgical intervention and those radiograph with poor quality were excluded in the study. Diagnosis of ZACD was done if clear, welldefined unilocular or multilocular or trabecular radiolucency of the zygomatic arch or articular eminence posterior to the zygomatico-temporal suture was recognized. The data were tabulated and subjected to statistical analysis.

\section{Results}

Out of 1000 study subjects, ZACDs were found in 30 , giving an overall prevalence of $3.0 \%$. The mean age of subjects with ZACDs was 30.2 years. Out of 30 ZACDs, seventeen were in group I, seven in group II, five in group III and one in group IV. Out of 30 ZACDS, eighteen were in males and twelve were in females. The mean age of male subjects with ZACDs was 31.3 years and mean age of females with ZACDs was 28.9 yrs. The male to female ratio was 3:2.

Among the 30 ZACDs, twenty were of the unilocular type and eight were multilocular and one with unilocular on right side \& multilocular type on left side. Among the thirteen ZACDs found on the right side, six were of the unilocular type and seven were of the multilocular type. On left side, among four ZACDs, one was multilocular type and three were unilocular type (Figurel). Among 30 ZACDs, seventeen were unilateral (Figure 2) and thirteen were bilateral. Among the 17 unilateral ZACDs, nine were seen in males and eight in females and thirteen were localized on the right side and four on the left side. Of the thirteen bilateral ZACDs, nine were in males, and four were in females (Graph 1 and 2).

\section{Discussion}

The cause of ZACD is unknown but may be similar to that of pneumatization of the mastoid process. Pneumatization begins with the formation of small osseous cavities created by normal periosteal activity. The primary regions of pneumatization of the temporal bone consist of the middle ear, squamomastoid (mastoid), perilabyrinthine, petrous apex, and accessory. The accessory regions include the squamous, the zygomaticooccipital, and the styloid. The tegmental or periantral air cell may extend into the zygomatic arch, producing the ZACD. The prevalence of ZACDs in the present study was $3.0 \%$. The mean age of the subjects with ZACDs was 30.2 years. The incidence of ZACDs decreased with age, as found in other studies as well. There were seventeen unilateral ZACDs and thirteen bilateral ZACDs in the present study. This suggests that ZACDs mostly occur unilaterally, which is consistent with previous studies. $^{3}$ 


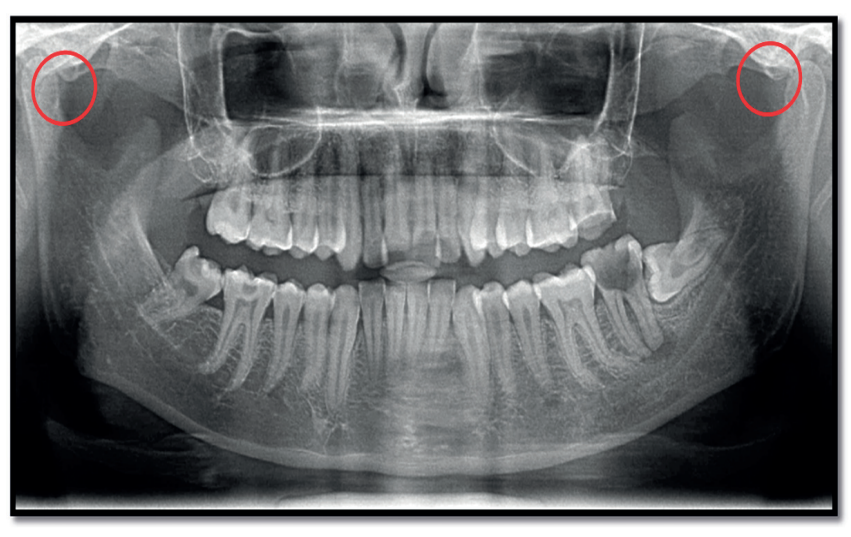

Figure 1: Panoramic radiograph showing unilocular ZACDs on right side and multilocular on left side.

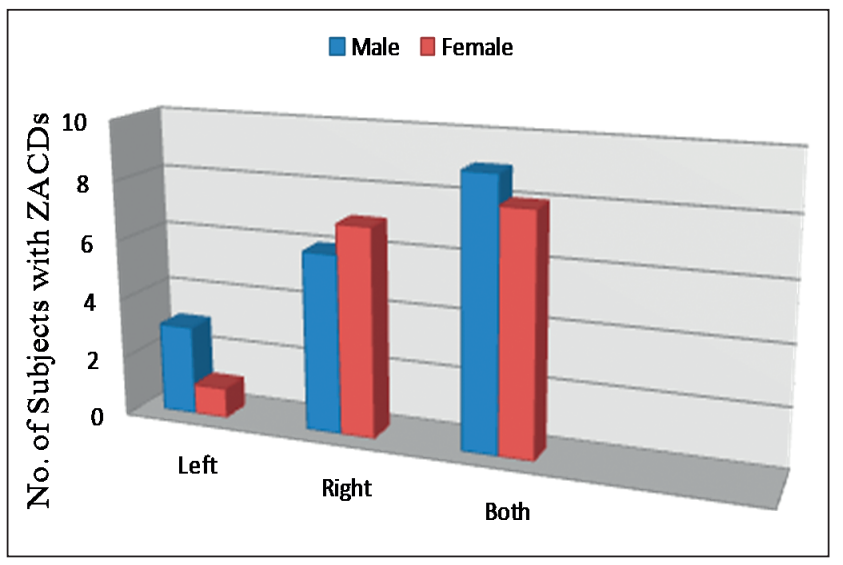

Graph 1: Distribution of ZACDs with respect to side and gender.

Among the seventeen unilateral ZACDS, thirteen occurred on theright sideand four occurred on the left side. The reason for this preference for the right side is not known. In contrast to our findings, Carter et al. and Park et al have reported an al most equal distribution of ZACDs. ${ }^{4}$ Among the 30 ZACDs, twenty were unilocular and eight were multilocular and one with unilocular on right side and multilocular type on left side, making the unilocular type by far the more common type in our study, though there have been other studies that have reported an almost equal number of unilocular and multilocular ZACDs, or multilocular a more common type. ${ }^{5}$

These differences might have been because of variations in the sample sizes as well as dueto inter-

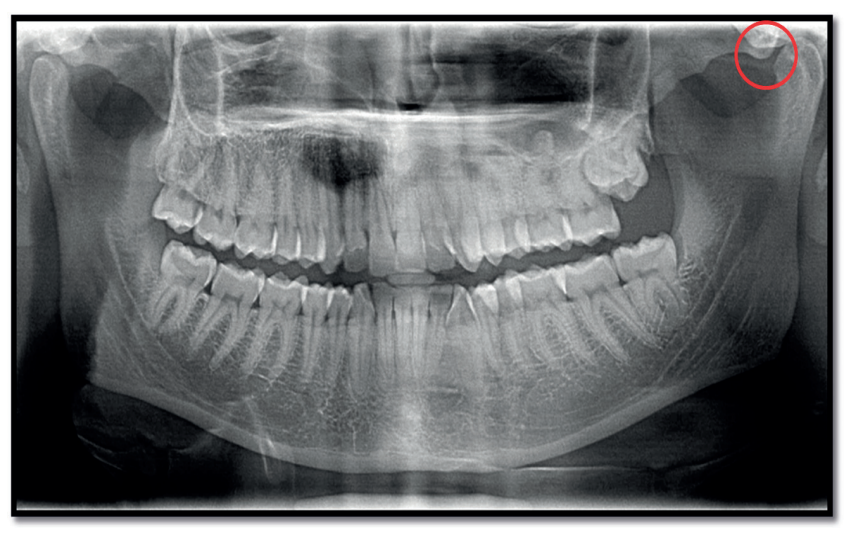

Figure 2: Panoramic radiograph showing unilateral ZACDs on left side.

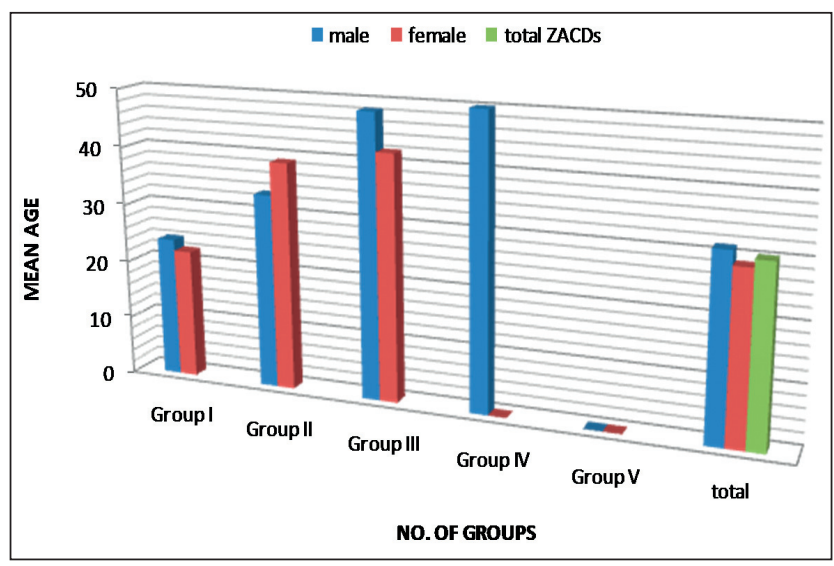

Graph 2: Distribution of ZACDs with respect to Number of Groups and mean age in between male and female individuals.

observer variability in determining the types of ZACDs. Hollingshead pointed out that the accessory air cells begin to pneumatize after puberty and achieve full size after several years as with mastoid air cells proper. The failure to detect before the second half of the second decade of life might be due to the fact that the process of pneumatization does not become extensive enough to be radiographically evident. The cases of ZACD were found in a broad range of patient ages but it did not appear over 60 years. ${ }^{6-8}$

All of theseries including this study showed low prevalence. Two possible reasons for ZACD's being seen less often are: 1) The number of ZACD may be small as there is a wide variability in the extent of accessory air cell of temporal bone and 2) In 
panoramic radiograph, radiographic visualization of ZACD is more difficult because there are superimposition of adjacent anatomic structures. High-resolution CT can give a better visualization in the evaluation of bony structure allowing exact delineation of temporal air spaces, but it is not justified because of cost and inconvenience. ${ }^{9-13}$

The differential diagnosis of radiolucencies within the zygomatic arch include ZACD, aneurysmal bone cyst, hemangioma, giant cell tumor, eosinophilic granuloma, fibrous dysplasia, and metastatic tumor. Only the ZACD occurs in the zygomatic arch with any frequency and presents as an asymptomatic, nonexpansile, nondestructive radiolucency detected incidentally on radiograph. All of the other entities in the differential diagnosis including osseous hemangioma is a rare lesion in zygoma and would be characterized by enlarging and painful cheek, bony expansion with cortical destruction and frequently mixed density lesions. ${ }^{14-15}$

The clinical significance of ZACD is that they represent sites of minimal resistance and thus facilitate the spread of various pathologic processes into the TMJ such as tumors, inflammation or fractures and it can even complicate TMJ surgery. While the ZACD requires no treatment, one caveat is in order. I nadvertent violation of an air cell during eminectomy, producing communication with the infratemporal or middle cranial fossa poses the genuine danger of intracranial infection and/or hemorrhage. This point outs the need for thorough pre-operative imaging evaluation. ${ }^{16-18}$

\section{Conclusion}

In conclusion, younger peoplearemore involved compared to the other studies. Due to the fragile and formidable nature of these defects, clinicians who are planning to perform temporomandibular joint surgery should be extra cautious when dealing with these entities especially in young people in this population. Hence, knowledge of the ZACD may be helpful in the interpretation of imaging studies, including panoramic radiographs, in the planning of surgical treatment of TMJ and in understanding the spread of pathological processes into the joint.

\section{References}

1. Tremble GE. Pneumatization of the temporal bone, Arch Otolaryngol 1934; 19:172-182.

2. Roser SM, Rudin DE, Brady FA. Unusual bony lesion of the zygomatic arch. J Oral Med 1976; 31:72-73.

3. Tyndall DA, Matteson SR. The zygomatic air cell defect on panoramic radiographs. Oral Surg Oral Med Oral Pathol 1987; 64:373-376.

4. Carter LC, Haller AD, Calamel AD, Pfaffenbach AC. Zygomatic air cell defect (ZACD): Prevalence and characteristics in a dental clinic outpatient population. Dentomaxillofac Radiol 1999; 28:116-122.

5. Beaumont GD. The effects of exclusion of air from pneumatized bones. J Laryngol Otol 1966; 80:236-249.

6. Kulikowski BM, Schow SR, Kraut RA. Surgical management of a pneumatized articular eminence of the temporal bone. J Oral Maxillofac Surg 1982; 40:311-313.

7. Deluke DM. Pneumatization of the articular eminence of the temporal bone. Oral Surg Oral Med Oral Pathol Oral Radiol Endod 1995; 79:3-4.

8. Weinberg S. Eminectomy and meniscorrhaphy for internal derangements of the temporomandibular joint. Oral Surg Oral Med Oral Pathol 1984; 57:241-249.

9. Tyndall DA, Matteson SR. Radiographic appearance and population distribution of the pneumatized articular eminence of the temporal bone. J Oral Maxillofac Surg 1985; 43:493-497.

10. Kaugars GE, Mercuri LG, Laskin DM. Pneumatization of the articular eminence of the temporal bone: prevalence, development, and surgical treatment. J Am Dent Assoc 1986; 113:55-57.

11. Groel R, Fleischmann B. The pneumatic spaces of the temporal bone: relationship to the temporomandibular joint. Dentomaxillofac Radiol 1999; 28:69-72.

12. Virapongse C, Sarwar M, Bhimani S, Sasaki C, Shapiro R. Computed tomography of temporal bone pneumatization: 1. Normal pattern and morphology. AJ NR 1985; 6:551-559.

13. Park YH, Lee SK, Park BH, Son HS, Choi M, Choi KS, et al. Radiographic evaluation of the Zygomatic air cell defect. Korean J Oral Maxillofac Radiol 2002; 32:207-211.

14. Hollinshead WH. Anatomy for surgeons; Head and neck. 2nd ed. New York: Harper and Row; 1968 p. 190-194.

15. Som PM, Curtin HD. Head and neck imaging. 3rd ed. St. Louis: Mosby Co; 1996 p. 1300.

16. Schillinger R. Pneumatization of the mastoid: a roentgen study. Radiology 1939; 33:54-67.

17. Shapiro R. Radiology of the normal skull. Chicago: Year Book Medical Co; 1981 p. 326-340.

18. Allam AF. Pneumatization of the temporal bone, Ann Otol Rhinol Laryngol 1969; 78:49-64. 